\title{
Ischemic Preconditioning: Neuronal Survival in the Face of Caspase-3 Activation
}

\author{
Hidenobu Tanaka, ${ }^{* \dagger}$ Hidenori Yokota, ${ }^{\star}$ Teresa Jover, ${ }^{\star}$ Irene Cappuccio, ${ }^{\star}$ Agata Calderone, Monica Simionescu, \\ Michael V. L. Bennett, and R. Suzanne Zukin \\ Department of Neuroscience, Albert Einstein College of Medicine, Bronx, New York 10461-1975
}

\begin{abstract}
Apoptosis is an evolutionarily conserved process critical to tissue development and tissue homeostasis in eukaryotic organisms and, when dysregulated, causes inappropriate cell death. Global ischemia is a neuronal insult that induces delayed cell death with many features of apoptosis. Ischemic preconditioning affords robust protection of CA1 neurons against a subsequent severe ischemic challenge. The molecular mechanisms underlying ischemic tolerance are unclear. Here we show that ischemia induces pronounced caspase-3 activity in naive neurons that die and in preconditioned neurons that survive. Preconditioning intervenes downstream of proteolytic processing and activation of caspase- 3 (a protease implicated in the execution of apoptosis) and upstream of the caspase- 3 target caspase-activated DNase (CAD, a deoxyribonuclease that catalyzes DNA fragmentation) to arrest neuronal death. We further show that global ischemia promotes expression of the pro-survival inhibitor-of-apoptosis (IAP) family member cIAP, but unleashes Smac/DIABLO (second mitochondria-derived activator of caspases/direct IAP-binding protein with low pI), a factor that neutralizes the protective actions of IAPs and promotes neuronal death. Preconditioning blocks the mitochondrial release of Smac/DIABLO, but not the ischemiainduced upregulation of IAPs. In the absence of Smac/DIABLO, cIAP halts the caspase death cascade and arrests neuronal death. These findings suggest that preconditioning preserves the integrity of the mitochondrial membrane, enabling neurons to survive in the face of caspase activation.
\end{abstract}

Key words: neuronal death; apoptosis; caspase death cascade; DNA fragmentation factor; ischemic insults; ischemic preconditioning; neuroprotection; tolerance

\section{Introduction}

Ischemic tolerance is a well known phenomenon in which brief ischemic insults (ischemic preconditioning) confer robust neuroprotection to hippocampal CA1 neurons against a subsequent severe ischemic challenge (Kirino et al., 1991; Kitagawa et al., 1991; Liu et al., 1992; Nishi et al., 1993; Simon et al., 1993; Wu et al., 2001). Ischemic tolerance can also be induced in vivo by spreading depression (Kawahara et al., 1997), hypoxia (Gidday et al., 1999), activation of A1 adenosine receptors (Heurteaux et al., 1995), and inhibition of oxidative phosphorylation (Riepe et al., 1997) and in vitro by exposure to excitotoxins (Grabb and Choi, 1999). Although the molecular mechanisms underlying ischemic tolerance are not yet fully delineated, the considerable delay from

Received 0ct. 1, 2003; revised Jan. 16, 2004; accepted Jan. 20, 2004.

This work was supported by National Institutes of Health Grants NS20752, NS31282 (R.S.Z.), and NS45287 (M.V.L.B.), and the F. M. Kirby Foundation. M.V.L.B. is the Sylvia and Robert S. Olnick Professor of Neuroscience. We remember and honor Hidenobu Tanaka for his scientific insight, creativity, technical acumen, and warmth and sensitivity as a human being. We thank Dr. Anna Francesconi for helpful scientific discussions and Roodland Regis and Monique Bryan for technical assistance.

${ }^{*}$ H.T., H.Y., T.J., and I.C. contributed equally to this work.

${ }^{\dagger}$ Deceased, 0ct. 13, 2002.

Correspondence should be addressed to Dr. R. Suzanne Zukin, Department of Neuroscience, Albert Einstein College of Medicine, 1300 Morris Park Avenue, Bronx, NY 10461. E-mail: zukin@aecom.yu.edu.

A. Calderone's present address: Department Genetic Medicine, Weill Medical College of Cornell University, New York, NY 10021.

DOI:10.1523/JNEUROSCI.5475-03.2004

Copyright $\odot 2004$ Society for Neuroscience $\quad$ 0270-6474/04/242750-10\$15.00/0 the preconditioning stimulus until onset of ischemic tolerance is consistent with a role for transcriptional changes in adaptation (Kirino, 2002).

Transient, severe global ischemia arising in humans as a consequence of cardiac arrest or cardiac surgery or induced experimentally in animals, leads to selective and delayed neuronal death, particularly of pyramidal neurons in the hippocampal CA1 (for review, see MacManus and Buchan, 2000; Yamashima, 2000; Graham and Chen, 2001). The relative contributions of apoptotic and necrotic death to ischemia-induced neuronal loss remain controversial. Strong evidence in support of apoptosis, defined as activation of specific signaling cascades that result in cell suicide, comes from molecular studies. Injurious stimuli such as ischemia disrupt the integrity of the mitochondrial membrane, leading to the release of cytochrome $c$ (Zou et al., 1997; Ouyang et al., 1999) and activation of caspase-9, an "initiator" caspase (Krajewski et al., 1999; Ouyang et al., 1999) and caspase-3, a "terminator" caspase implicated in the execution step of apoptosis (Chen et al., 1998; Jover et al., 2002). The importance of caspase-3 activation in ischemic death is underscored by the finding that Z-DEVD-FMK, a selective caspase-3 inhibitor, affords robust protection of neurons against ischemic death (Hara et al., 1997; Chen et al., 1998). Caspase-3 promotes cell death by proteolytic cleavage of target proteins, including the inhibitory subunit of caspase-activated DNase (ICAD), which liberates activated CAD (for review, see Nagata, 2000), the DNA repair and surveillance 
enzyme poly (ADP-ribose) polymerase (PARP-1) and the nuclear lamins, proteolysis of which mediates nuclear shrinking and budding (for review, see Cohen, 1997; Nicholson and Thornberry, 1997; Hengartner, 2000). After activation, CAD cuts genomic DNA between the nucleosomes to generate DNA fragments of graded lengths ("DNA laddering") in the nuclei of neurons destined to die (for review, see Nagata, 2000).

The present study was undertaken to examine a possible role for the caspase cascade and apoptotic signaling proteins in ischemic tolerance. Here we show that induction of global ischemia in preconditioned animals triggers activation of the initiator protease caspase- 9 and of the terminator protease caspase-3, but fails to increase nuclear CAD, induce $\mathrm{p} 75^{\mathrm{NTR}}$, or cause DNA fragmentation in neurons destined to die. Thus, ischemic preconditioning acts downstream of caspase- 3 activation and upstream of its target CAD to prevent arrest neuronal death. We further show that global ischemia promotes upregulation of cellular inhibitorof-apoptosis protein (cIAP) and heat shock protein 70 (HSP70) and the mitochondrial release of second mitochondria-derived activator of caspases/direct IAP-binding protein with low pI (Smac/DIABLO), and that preconditioning blocks the mitochondrial release of Smac/DIABLO, with little or no effect on cIAP-2 and HSP70 expression. In the absence of Smac/DIABLO, IAPs bind and inhibit activated caspases and thereby halt the self-amplifying caspase death cascade. These findings suggest that preconditioning preserves the integrity of the mitochondrial membrane in the face of ischemic insults, enabling CA1 neurons to survive caspase- 3 activation.

\section{Materials and Methods}

Ischemic preconditioning and global ischemia. Age-matched male Sprague Dawley rats (Charles River Laboratories, Wilmington, MA) were maintained in a temperature- and light-controlled environment with a 14/10 $\mathrm{hr}$ light/dark cycle and were treated in accordance with the principles and procedures of the National Institutes of Health Guidelines for the Care and Use of Laboratory Animals. All protocols were approved by the Institutional Animal Care and Use Committee of the Albert Einstein College of Medicine. Animals were subjected to global ischemia by fourvessel occlusion (4 min for preconditioning; $10 \mathrm{~min}$ for global ischemia), followed by reperfusion as described (Kinouchi et al., 1993; Calderone et al., 2003). For sham operation, animals were subjected to the same anesthesia and surgical exposure procedures, except that the carotid arteries were not occluded. Body temperature was monitored and maintained close to $37.5 \pm 0.5^{\circ} \mathrm{C}$ with a rectal thermistor and heat lamp until the animal had fully recovered from anesthesia. The rare animals that exhibited obvious behavioral manifestations (abnormal vocalization when handled, generalized convulsions, loss of $>20 \%$ body weight by $3-7 \mathrm{~d}$ or hypoactivity) and animals that failed to show complete loss of the righting reflex from $2 \mathrm{~min}$ after occlusion was initiated and anesthesia was discontinued until the end of occlusion were excluded. Histology and neuronal counts from six to eight rats per group (four sections per animal) were as described (Calderone et al., 2003). Statistical analysis was assessed by ANOVA, followed by Scheffe's post hoc tests. Ischemic preconditioning and global ischemia in gerbils were as described (Tanaka et al., 2002).

Antibodies. The following antibodies were used in this study: (1) an anti-caspase-9 p35 polyclonal antibody that recognizes both procaspase- 9 and activated caspase- 9 p35 (1:1000; Santa Cruz Biotechnology, Santa Cruz, CA); (2) anti-caspase-3p20, a goat polyclonal antibody that recognizes both procaspase-3 and activated caspase-3 (1:75; Santa Cruz Biotechnology); (3) an anti-CAD polyclonal antibody that is specific for activated CAD (1:1000; FL-338; Santa Cruz Biotechnology); (4) an anti-PARP polyclonal antibody raised against a synthetic peptide corresponding to amino acids $764-1014$ within the $C$ terminus of human PARP; this antibody reacts with the 112 and $85 \mathrm{kDa}$ forms of PARP (1:200; H-250; Santa Cruz Biotechnology); (5) anti-p75 ${ }^{\text {NTR }}$ polyclonal antibody directed to the cytoplasmic domain of human p $75^{\text {NTR }}$ (1:4000; gift from Dr. Moses V. Chao, New York University School of Medicine, New York, NY); (6) anti-XIAP polyclonal antibody raised against a synthetic peptide corresponding to residues around amino acid 240 of XIAP; this antibody is specific for XIAP and does not react with other inhibitors of apoptosis (1:1000; Cell Signaling Technology, Beverly MA); (7) anticIAP-2 polyclonal antibody raised against a synthetic peptide corresponding to amino acid residues 507-524 of human cIAP-2; this antibody is highly specific for human and rat cIAP-2, does not react with cIAP-1 ( $1.5 \mu \mathrm{g} / \mathrm{ml}$; R \& D Systems, Inc., Minneapolis MN); (8) rabbit anti-HSP70 polyclonal antibody-specific for the inducible form of HSP70 (HSP72) and does not cross-react with constitutive Hsc70 (1: 100,000; SPA-812; Stressgen Biotechnologies, Victoria, British Columbia, Canada); (9) anti-cytochrome $c$ mouse monoclonal antibody raised against peptides $1-80,81-104$, and 66-104 of pigeon cytochrome $c$ (1.5 $\mu \mathrm{g} / \mathrm{ml}$; clone 7H8.2C12; BD Biosciences, San Diego CA); and (10) antiSmac/DIABLO, raised against a synthetic peptide corresponding to amino acid residues 222-237 of murine Smac/DIABLO $(0.5 \mu \mathrm{g} / \mathrm{ml}$; Axxora, LLC San Diego, CA). Secondary antibodies were horseradish peroxidase (HRP)-conjugated rabbit anti-goat IgG (1:2000; Vector Laboratories, Burlingame, CA) for caspase-3, goat anti-rabbit IgG (1:2000; Vector Laboratories) for caspase-9, CAD, PARP-1, p75 ${ }^{\text {NTR }}$, XIAP, cIAP-2, and HSP70 or horse anti-mouse IgG (1:2000; Vector Laboratories) for cytochrome $c$ and Smac/DIABLO.

Immunocytochemistry. Immunolabeling was performed as described (Calderone et al., 2003). In brief, gerbils were killed under deep anesthesia by transcardiac perfusion with $4 \%$ paraformaldehyde and $0.125 \%$ glutaraldehyde at $6,12,24,72 \mathrm{hr}$, or $7 \mathrm{~d}$ after sublethal ischemia, global ischemia, and sublethal ischemia followed by global ischemia, or $24 \mathrm{hr}$ after sham operation. Brains were rapidly removed, postfixed with $4 \%$ paraformaldehyde for $2 \mathrm{hr}$, and cut into sections $(40 \mu \mathrm{m})$ in the coronal plane of the dorsal hippocampus by cryotome. Sections were blocked and processed for labeling with anti-caspase-3p20. The caspase-3 signal was amplified with a biotin-conjugated rabbit antibody against goat $\operatorname{IgG}(1$ : 200; $1 \mathrm{hr}$ at room temperature; Vector Laboratories). Sections were incubated and processed with avidin-biotin peroxidase complex (Vectastain ABC kit; Vector Laboratories). The specificity of the immunolabeling was confirmed in separate control experiments in which sections were processed with pre-immune rabbit IgG in place of primary antibody; no detectable labeling was observed. Images were viewed through a Nikon ECLIPSE TE300 inverted microscope and acquired with a SPOT RT CCD-cooled camera equipped with diagnostic software version 3.0.

Western blotting. Western blot analysis was performed as described (Opitz et al., 2000). Tissue samples of the CA1 were microdissected. For $\mathrm{CAD}$, nuclear and cytosolic fractions were isolated as described (Calderone et al., 2003). For Smac/DIABLO and cytochrome $c$, mitochondria and cytosolic fractions were isolated. In brief, microdissected tissue from one rat was transferred to lysis buffer containing in mM: 5 HEPES, 1 $\mathrm{MgCl}_{2}, 2$ EGTA, 1 DTT, and 300 sucrose supplemented with a $1 \%$ cocktail of protease and phosphatase inhibitors, incubated $\left(30 \mathrm{~min}\right.$ at $\left.4^{\circ} \mathrm{C}\right)$ and homogenized with a Dounce homogenizer. The resulting lysate was centrifuged at $3200 \mathrm{rpm}\left(10 \mathrm{~min}\right.$ at $\left.4^{\circ} \mathrm{C}\right)$ to separate cytoplasmic fraction (supernatant) from the nuclear fraction (pellet). To isolate mitochondria, the supernatant was centrifuged again at $10,500 \mathrm{rpm}\left(20 \mathrm{~min}\right.$ at $\left.4^{\circ} \mathrm{C}\right)$ to separate the mitochondrial fraction (pellet) from the cytosolic fraction (supernatant). Protein concentration was by BCA kit (Pierce, Rockford, IL). Aliquots of protein $(30-40 \mu \mathrm{g})$ were loaded on 18 or $10 \%$ polyacrylamide gels and subjected to gel electrophoresis. Bands were transferred to a nitrocellulose membrane and incubated with antibodies against caspase-9, caspase-3p20, CAD, PARP-1, XIAP, cIAP, HSP70, cytochrome $c$, and Smac/DIABLO. Secondary antibodies were horseradish peroxidase (HRP)-conjugated rabbit anti-goat IgG, goat anti-rabbit IgG, or goat anti-mouse IgG (Vector Laboratories). Membranes were washed and reacted with enhanced chemiluminescence reagent (ECL; Amersham Biosciences, Little Chalfont, UK). Purity of nuclear and cytosolic fractions was verified by labeling with the anti-PARP-1 antibody. Purity of mitochondrial and cytosolic fractions was verified by labeling with the cytochrome $c$ antibody. Band density values were normalized to actin 
(whole cell and cytosolic samples) or, in the case of nuclear and mitochondrial fractions (which do not contain actin), equal loading of samples was performed. Mean band densities for protein samples from experimental animals were normalized to the corresponding values for samples from control animals. Statistical significance was by ANOVA and post hoc Scheffe's tests.

Caspase- 3 activity assay. Caspase- 3 activity assays were performed on sections of fresh-frozen rat brain using the FAM-DEVD-FMK caspase detection kit according to manufacturer's instructions (APO LOGIXTM). FAM-DEVD-FMK is a carboxy-fluorescein analog of zDEVD-FMK, a potent inhibitor of caspase- 3 that enters the cell and irreversibly binds to activated caspase-3. Brain sections were viewed under a Nikon (Tokyo, Japan) ECLIPSE TE-300 fluorescent microscope equipped with an image analysis system at an excitation wavelength of $488 \mathrm{~nm}$ and emission wavelength of $565 \mathrm{~nm}$. Images were acquired with a SPOT RT CCD-cooled camera with diagnostic software version 3.0. For quantitation of caspase-3 activity, images were analyzed by NIH Image 1.61 software. Statistical analysis was by ANOVA and Newman-Keuls test.

Terminal deoxynucleotidyl transferase-mediated biotinylated UTP nick end labeling and $p 75^{N T R}$ immunolabeling. To detect DNA fragmentation in neurons undergoing end-stage apoptosis, animals were killed at $48 \mathrm{hr}$ and coronal sections $(18 \mu \mathrm{m})$ of fresh-frozen rat brain were cut by cryotome and processed for Hoechst/ terminal deoxynucleotidyl transferasemediated biotinylated UTP nick end labeling (TUNEL)/p $75^{\mathrm{NTR}}$ triple labeling using an in situ cell death detection kit as per the manufacturer's instructions (Roche Molecular Biochemicals, Mannheim, Germany). In brief, sections were fixed in $4 \%$ paraformaldehyde for $20 \mathrm{~min}$ at $4{ }^{\circ} \mathrm{C}$ and processed for TUNEL labeling. Sections were then blocked, labeled with an anti-p $75^{\text {NTR }}$ antibody, followed by biotinylated goat anti-rabbit IgG (1:200) and avidin-conjugated Texas Red (1:200; Vector Laboratories). During washes, sections were labeled with the nuclear stain Hoechst 33342 according to manufacturer's instructions (Molecular Probes, Eugene, OR). Specificity of immunolabeling was assessed as above. Images were viewed under a Nikon ECLIPSE TE300 fluorescence microscope and acquired with a SPOT RT CCD-cooled camera equipped with diagnostic software version 3.0. Settings were held constant for imaging of sections from control and experimental animals. TUNEL-positive cells were identified directly by the fluorescence signal of incorporated fluorescein-dUTP. Positive cells in 24 fields sampled from the hippocampal CA1 subfields from three animals (eight fields each) were scored at 72 $\mathrm{hr}$ for $\mathrm{p} 75^{\mathrm{NTR}}$ immunolabeling and TUNEL signal and are expressed as a percentage of the total $\mathrm{p} 75^{\mathrm{NTR}}$ or total TUNEL-positive cells \pm SEM values. Statistical analysis was by ANOVA, followed by Newman-Keuls test.

\section{Results}

\section{Preconditioning affords robust protection of CA1 neurons}

To examine molecular mechanisms underlying the neuroprotective effects of preconditioning, rats were subjected to sham operation, preconditioning, global ischemia, or preconditioning followed by global ischemia, and neuronal death was assessed histologically at $7 \mathrm{~d}$. Global ischemia afforded highly delayed, highly selective death of pyramidal cells in the hippocampal CA1, evident at $7 \mathrm{~d}$ (Fig. 1) (see also Calderone et al., 2003). Neuronal death in the CA1 was extensive; the few remaining pyramidal neurons were severely damaged and appeared pyknotic. Neuronal death was specific in that inhibitory interneurons of the CA1 survived and little or no cell loss occurred in the nearby CA2 or transition zone, CA3, or dentate gyrus. Neuronal death was delayed in that little or no death was manifested at $48 \mathrm{hr}$ (data not illustrated, but see Pulsinelli et al., 1982; Calderone et al., 2003). Preconditioning did not induce neuronal damage (Fig. $1 c, d$ ), but afforded robust protection of CA1 neurons against a subsequent global ischemic insult at $48 \mathrm{hr}$ (ischemic tolerance) (Fig. 1g,h). These findings were validated by neuronal counts (Fig. 1i) and corroborate findings in rats (Liu et al., 1992; Nishi et al., 1993;

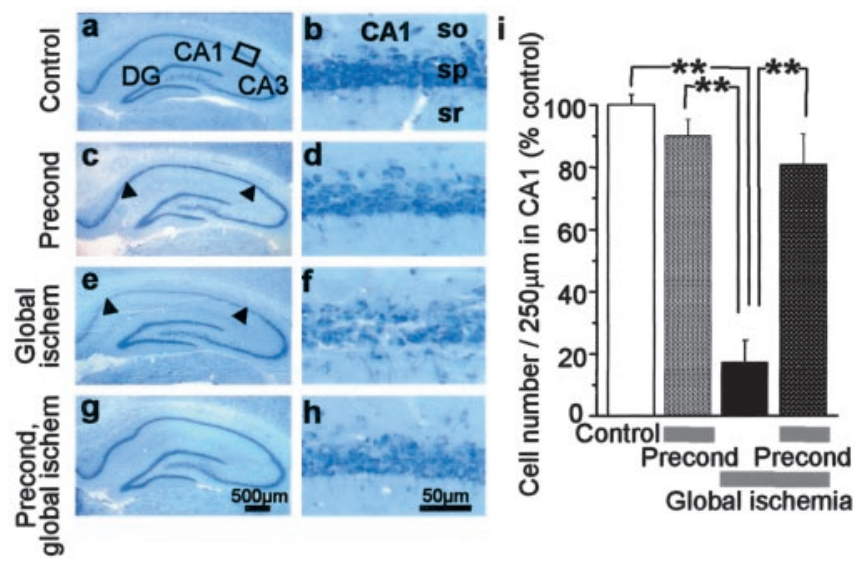

Figure 1. Ischemic preconditioning affords neuroprotection against ischemia-induced neuronal death. Toluidine blue-stained coronal brain sections at the level of the dorsal hippocampus from sham $(n=8 ; a, b)$ and experimental rats subjected to ischemic preconditioning $(n=$ $8 ; c, d)$, global ischemia $(n=8 ; e, f)$ or to preconditioning, followed by global ischemia $(n=8$; $g, h)$ at $7 \mathrm{~d}$ after reperfusion. Preconditioning did not induce neuronal death $(c, d)$. Global ischemia induced loss of pyramidal neurons in the hippocampal CA1; cell loss was not detected in CA3 or dentate gyrus $(e, f)$. Preconditioning afforded robust neuroprotection against subsequent global ischemia-induced death $(g, h)$. so, Stratum oriens; sp, stratum pyramidale; sr, stratum radiatum. Scale bars: $a, c, e, g, 500 \mu \mathrm{m} ; b, d, f, h, 50 \mu \mathrm{m}$. Quantitation of photomicrographs like those shown in $a-h$ (i). ${ }^{*} p<0.05$; ${ }^{* *} p<0.01$.

Simon et al., 1993) and gerbils (Kirino et al., 1991; Tanaka et al., 2002).

\section{Preconditioning does not block ischemia-induced caspase-9 activation}

Neuronal insults such as ischemia trigger upstream events, leading to the release of cytochrome $c$ from mitochondria (Ouyang et al., 1999; Sugawara et al., 1999) and formation of the apoptosome, which proteolytically processes procaspase- 9 to generate caspase-9 (Liu et al., 1996; Li et al., 1997; Zou et al., 1997). In neurons, procaspase- 9 is localized to mitochondria and in response to global ischemia is released concomitantly with cytochrome $c$ (Krajewski et al., 1999; Ouyang et al., 1999). We examined the effects of global ischemia on procaspase- 9 abundance and proteolytic processing by Western blot analysis of mitochondrial and cytosolic samples from microdissected CA1. In control animals, the abundance of procaspase- 9 (50 kDa band) in the mitochondria and that of cleaved (activated) caspase- $9(35 \mathrm{kDa}$ band) in the cytosol were low (Fig. $2 a-d$ ). Global ischemia caused a marked upregulation of procaspase- 9 in the mitochondria (increase to $206 \pm 9.3 \%$ of control) (Fig. $2 a$, third lane, $c$ ) and dramatic increase in the abundance of activated caspase- 9 in the cytosol, assessed at $24 \mathrm{hr}$ (increase of $35 \mathrm{kDa}$ species to $674 \pm$ $124 \%$ of the control value; $p<0.01$ vs control; $n=4$ ) (Fig. $2 b$, third lane, $d$ ) in confirmation of others (Krajewski et al., 1999; Ouyang et al., 1999; Henshall et al., 2001). Preconditioning, under conditions that afford robust neuroprotection, did not significantly alter the abundance of procaspase- 9 in the mitochondria (Fig. $2 a$, second lane, $c$ ), but markedly increased caspase- 9 in the cytosol of CA1 at $24 \mathrm{hr}$ (increase of $35 \mathrm{kDa}$ species to $373 \pm 80 \%$ of the control value; $p<0.05$ vs control) (Fig. $2 b$, second lane, $d$ ). Moreover, preconditioning did not alter the ischemia-induced upregulation of procaspase- 9 (Fig. $2 a$, fourth lane, $c$ ), but markedly enhanced the ischemia-induced increase in caspase- $935 \mathrm{kDa}$ species (increase to $1260 \pm 28 \%$ of the control value; $p<0.01$ vs control and vs global ischemia) (Fig. $2 a$, fourth lane, $c$ ). These findings are consistent with a model in which ischemia promotes the upregulation 


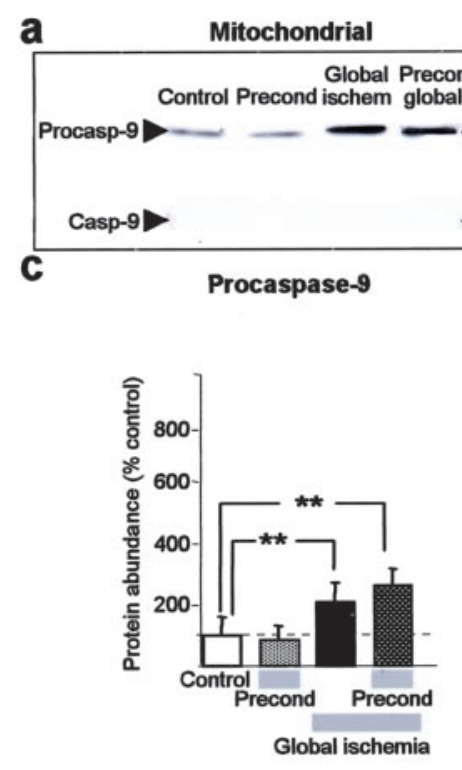

e

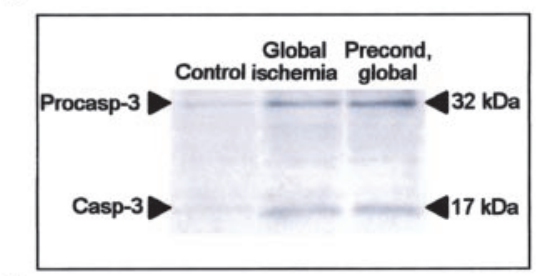

f

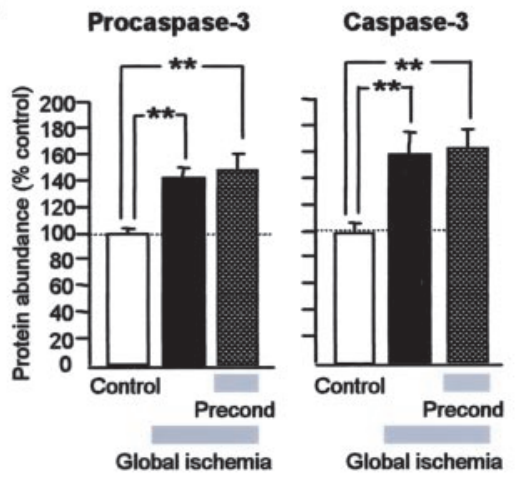

b

Cytosolic Global Precond, Control Precondischem global

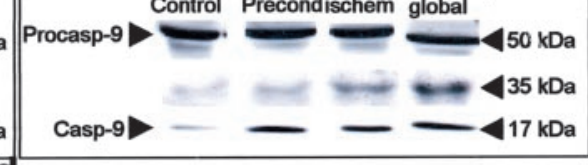

d Procaspase-9 Casp-9 $35 \mathrm{kDa}$ Casp-9 $17 \mathrm{kDa}$ Globl ischemia Globl ischemia Globl ischemia

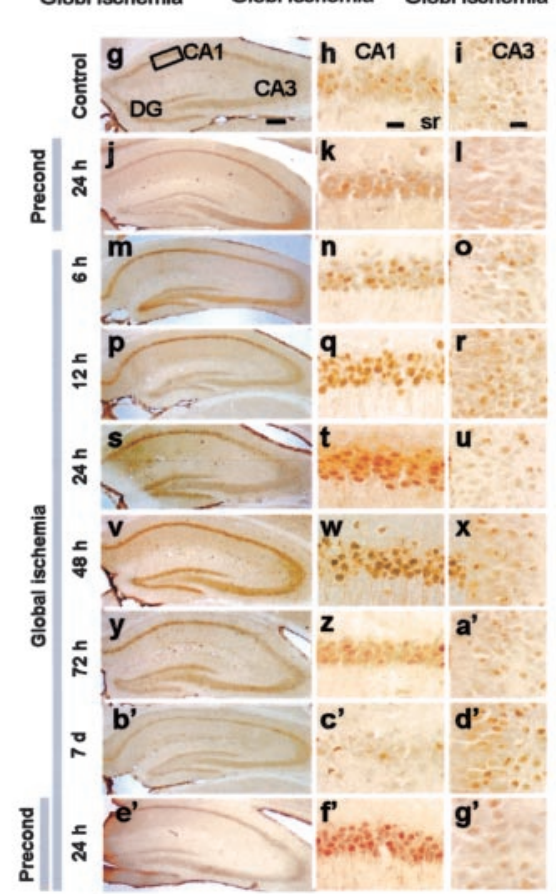

Figure 2. Global ischemia triggers activation of caspase- 9 and caspase- 3 in preconditioned neurons. Representative Western blots probed with anti-caspase- 9 for protein samples isolated from the mitochondrial $(a)$ and cytosolic $(b)$ fractions of CA1 from rats subjected to sham operation, preconditioning, global ischemia, or preconditioning followed by global ischemia and killed 24 hr after the last surgery. Relative abundance of procaspase- 9 and caspase- 9 in mitochondria $(c)$ and cytosol ( $d$ ).e, Representative Western blots probed with anti-caspase-3 (50 and 17 kDa bands, Cell Signaling Technology; 35 kDa band, Santa Cruz Biotechnology; see Materials and Methods); $f$, relative abundance of procaspase-3 (left graph) and caspase-3 17 kDa band (right graph) for samples isolated from the CA1 of animals as in $a$. Mean band densities of protein samples from experimental animals were normalized to the corresponding values for samples from control animals. Statistical significance was assessed by means of ANOVA, followed by Newman-Keuls test. $\left.{ }^{* *} p<0.01\right) . g, g^{\prime}$, Caspase-3 immunolabeling in sections of brain at the level of the dorsal hippocampus from control (sham-operated; $g-i)$ and experimental gerbils subjected to preconditioning at $24 \mathrm{hr}(j-l)$, global ischemia at $6 \mathrm{hr}(m-0), 12 \mathrm{hr}(p-r), 24 \mathrm{hr}(s-u), 48 \mathrm{hr}(v-x), 72 \mathrm{hr}\left(y-a^{\prime}\right)$ and $7 \mathrm{~d}\left(b^{\prime}-d^{\prime}\right)$, and preconditioning followed by global ischemia at $24 \mathrm{hr}$ after global ischemia $\left(e^{\prime}-g^{\prime}\right)$ after the last surgery. Scale bars: $400 \mu \mathrm{m}$ (low magnification); $50 \mu \mathrm{m}$ (high magnification).

and mitochondrial release procaspase-9, and its proteolytic cleavage to generate the $35 \mathrm{kDa}$ (activated) species in both naive and preconditioned animals, but do not distinguish between regulation at the transcriptional versus post-transcriptional level and/or relocalization between cellular compartments.
Preconditioning does not block caspase 3 upregulation or activation

Caspase- 3 is a critical target of caspase- 9 and downstream "terminator" protein implicated in the execution step of apoptosis (Cohen, 1997; Nicholson and Thornberry, 1997). In control animals, abundance of procaspase-3 (32 $\mathrm{kDa})$ and cleaved caspase-3 $(17 \mathrm{kDa})$ were low in CA1, as assessed by Western analysis (Fig. $2 e$, first lane, $f$ ). Global ischemia induced a marked increase in procaspase- 3 and cleaved (activated) caspase- 3 in CA1, evident at $24 \mathrm{hr}$ (procaspase- 3 , increase to $142 \pm 8 \%$ of control; $n=5$; $p<0.01$; caspase- 3 , increase to $161 \pm 13 \%$ of control; $n=5 ; p<$ 0.01 ) (Fig. $2 e$, second lane, $f$ ). Preconditioning under conditions that afford neuroprotection did not detectably alter the ischemia-induced upregulation or proteolytic processing of procaspase-3 (Fig. 2e, third lane, $f$ ).

To examine the localization of procaspase- 3 and caspase- 3 , we performed immunolabeling of brain sections with an anti-caspase- 3 antibody (Fig. $2 g, g^{\prime}$ ). In control animals, the caspase- 3 signal was low throughout the molecular layers of the hippocampus (Fig. $2 g-i$ ). Global ischemia induced a marked increase in expression and nuclear translocation of caspase- 3 in CA1 pyramidal neurons, evident at $6-72$ hr (Fig. $\left.2 m-a^{\prime}\right)$. These findings are in corroboration of Chen et al. (1998). The effects of ischemia on caspase- 3 expression were specific in that expression was not altered in the resistant CA3 (Fig. $20, r, u, x, a^{\prime}$ ) or dentate gyrus (Fig. $2 m, p, s, v, y)$. At $7 \mathrm{~d}$, the pyramidal cell layer was essentially ablated, and caspase- 3 immunolabeling was undetectable (Fig. $2 b^{\prime}$, $\left.c^{\prime}\right)$. Preconditioning under conditions that afford robust neuroprotection modestly and specifically enhanced caspase- 3 expression in CA1 pyramidal neurons, evident at $24 \mathrm{hr}$ after preconditioning (Fig. $2 j-l$ ), but did not alter the ischemiainduced increase in caspase- 3 expression (Fig. $2 e^{\prime}-g^{\prime}$ ).

Preconditioning induces a delayed, persistent block of caspase- 3 activity The results thus far demonstrate that global ischemia promotes upregulation of the "terminator" protease caspase-3, but do not distinguish between active and inactive protein. To directly measure caspase- 3 functional activity, we took advantage of FAM-DEVD-FMK, a fluorescein-tagged analog of zDEVD-FMK. FAM-DEVD-FMK is a potent and cell-permeant inhibitor of caspase-3, which enters cells and binds irreversibly to the active site of caspase- 3 , and thus provides a fluorescent indicator of the abundance of active caspase-3. In sections of control 
brain, caspase- 3 activity was low (Fig. $3 a$ ). Global ischemia induced a dramatic increase in caspase- 3 activity in CA 1 , evident at all times examined (Fig. $3 f-i, o$ ). The increase in caspase- 3 activity was specific in that it was not observed in the resistant CA3 or dentate gyrus. Preconditioning under conditions that afford robust neuroprotection induced a substantial, but lesser and evidently sublethal, increase in caspase- 3 activity in CA1 pyramidal neurons (Fig. $3 b-e$, $n$ ); caspase- 3 activity in preconditioned animals peaked at 12-48 hr and declined markedly by $72 \mathrm{hr}$, a time at which neuroprotection is still observed (Liu et al., 1992). Preconditioning enhanced the ischemiainduced increase in caspase- 3 functional activity observed at $6 \mathrm{hr}$, but caused a potent inhibition of caspase- 3 activity that persisted from $12 \mathrm{hr}$ to at least $48 \mathrm{hr}$ (Fig. $3 j-m, n$ ). These findings are consistent with a model in which preconditioning promotes expression of a potent inhibitor or negative modulator that directly binds activated caspase- 3 to halt the self-amplifying caspase death cascade such as, for example, the IAP (inhibitors-ofapoptosis) family of pro-survival proteins (see below).

\section{Preconditioning blocks the increase in}

\section{CAD in the nuclei of CA1 neurons}

We next examined a critical downstream target of caspase-3, ICAD (Nicholson and Thornberry, 1997). Caspase-3 cleaves the CAD-ICAD heterodimer to generate activated $\mathrm{CAD}$. Active $\mathrm{CAD}$ catalyzes internucleosomal cleavage of genomic DNA and promotes nuclear condensation, hallmarks of apoptotic cell death. We first examined protein abundance of CAD in neurons destined to die by Western blot analysis of nuclear and cytosolic samples of CA1. Global ischemia induced a marked increase in CAD in the nuclear fraction of the CA1 (Fig. 4a), with a more modest increase in the cytosolic fraction (Fig. 4c). These results are in corroboration of others (Cao et al., 2001). Preconditioning had little or no effect on the modest ischemia-induced increase in CAD expression in the cytosol (Fig. $4 d$ ), but greatly reduced the increase in CAD in the nuclei of CA1 neurons (Fig. $4 b)$. Thus, preconditioning blocks nuclear activation of CAD, a critical player in apoptotic cell death.

\section{Preconditioning blocks expression of $\mathrm{p} 75^{\mathrm{NTR}}$ and DNA fragmentation}

Activated CAD catalyzes internucleosomal cleavage of genomic DNA. If preconditioning indeed acts upstream of CAD activation, it would be expected to block DNA fragmentation in CA1 neurons destined to die. In the TUNEL technique used, a terminal deoxynucleotidyl transferase confers fluorescein "tags" to nicked ends present in fragmented DNA. p75 ${ }^{\text {NTR }}$ is a proapoptotic neurotrophin receptor that can trigger apoptotic cell death via a death-receptor-dependent pathway (Kaplan and Miller, 1997) and provides a marker for apoptotic cells (Roux et al., 1999;
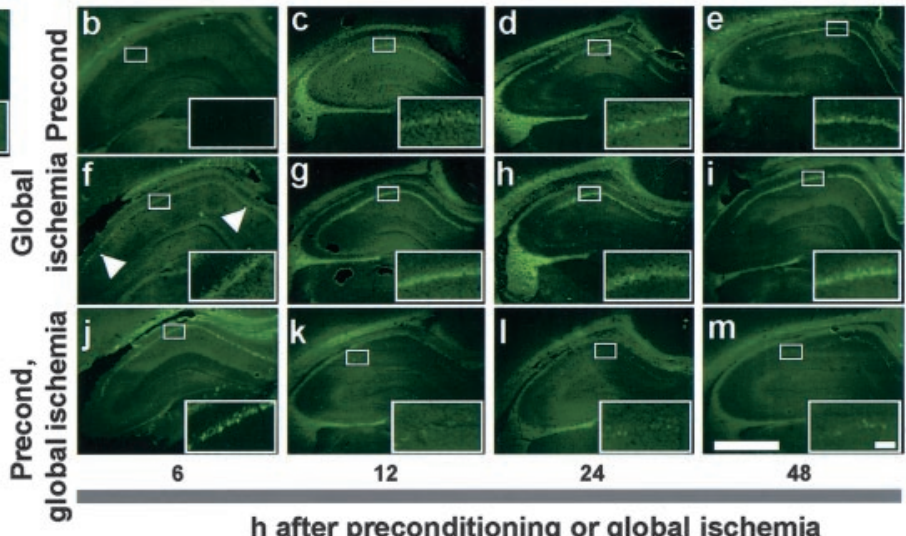

$\mathrm{h}$ after preconditioning or global ischemia
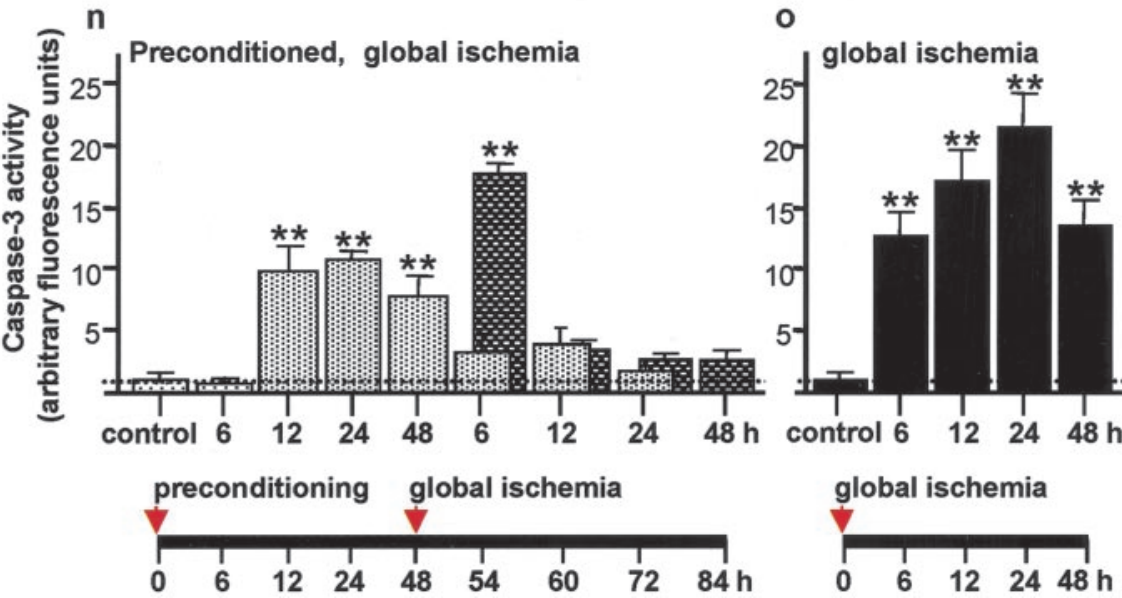

Figure 3. Global ischemia elicits marked, transient caspase-3 activity in preconditioned neurons. Representative brain sections of zDEVD-FMK, which binds irreversibly to activated caspase-3. Boxed regions are shown at higher magnitication in insets. $n$, Summary of data for animals subjected to preconditioning (light gray) or to preconditioning followed by global ischemia (dark gray). o, Summary of data for animals subjected to global ischemia only. Statistical significance was assessed by ANOVA, followed by Newman-Keuls test ( $\left.{ }^{* *} p<0.01\right)$. Scale bars: $400 \mu \mathrm{m}$ (low magnification); $50 \mu \mathrm{m}$ (high magnification).

Jover et al., 2002). To examine DNA fragmentation and induction of $\mathrm{p} 75^{\mathrm{NTR}}$ in neurons undergoing apoptosis, we labeled brain sections from control and experimental animals at $72 \mathrm{hr}$ after ischemia with TUNEL (to assess DNA fragmentation), antip75 ${ }^{\text {NTR }}$ antibody (to assess p75 NTR expression) and Hoechst 33342 (to assess cell numbers and possible alterations in nuclear morphology). In sections from control brain, TUNEL labeling and $\mathrm{p} 75^{\mathrm{NTR}}$ expression were undetectable in the pyramidal cell layers of the CA1 (Fig. $4 e-g$ ) and in other subfields of the hippocampus (data not illustrated). Global ischemia induced a marked increase in the incidence of TUNEL-positive and p75 ${ }^{\text {NTR }}$-positive neurons specifically in CA1 pyramidal neurons, evident at $72 \mathrm{hr}$ after ischemia (Fig. $4 k-m)(n=3$ per treatment group). There was a high coincidence of $\mathrm{p} 75^{\mathrm{NTR}}$ immunoreactivity and TUNEL-positive nuclei in the CA1 pyramidal cell layer; $70.2 \pm 3.1 \%$ of $775^{\mathrm{NTR}}$-positive CA1 nuclei were TUNELpositive and $68.5 \pm 2.9 \%$ of TUNEL-positive nuclei were p75 ${ }^{\text {NTR }}$-positive (Fig. $4 n-s$ ) in confirmation of Jover et al. (2002). Moreover, Hoechst stain revealed shrunken nuclei in many of the p75 ${ }^{\text {NTR }}$ - and TUNEL-positive cells (Jover et al., 2002). These 

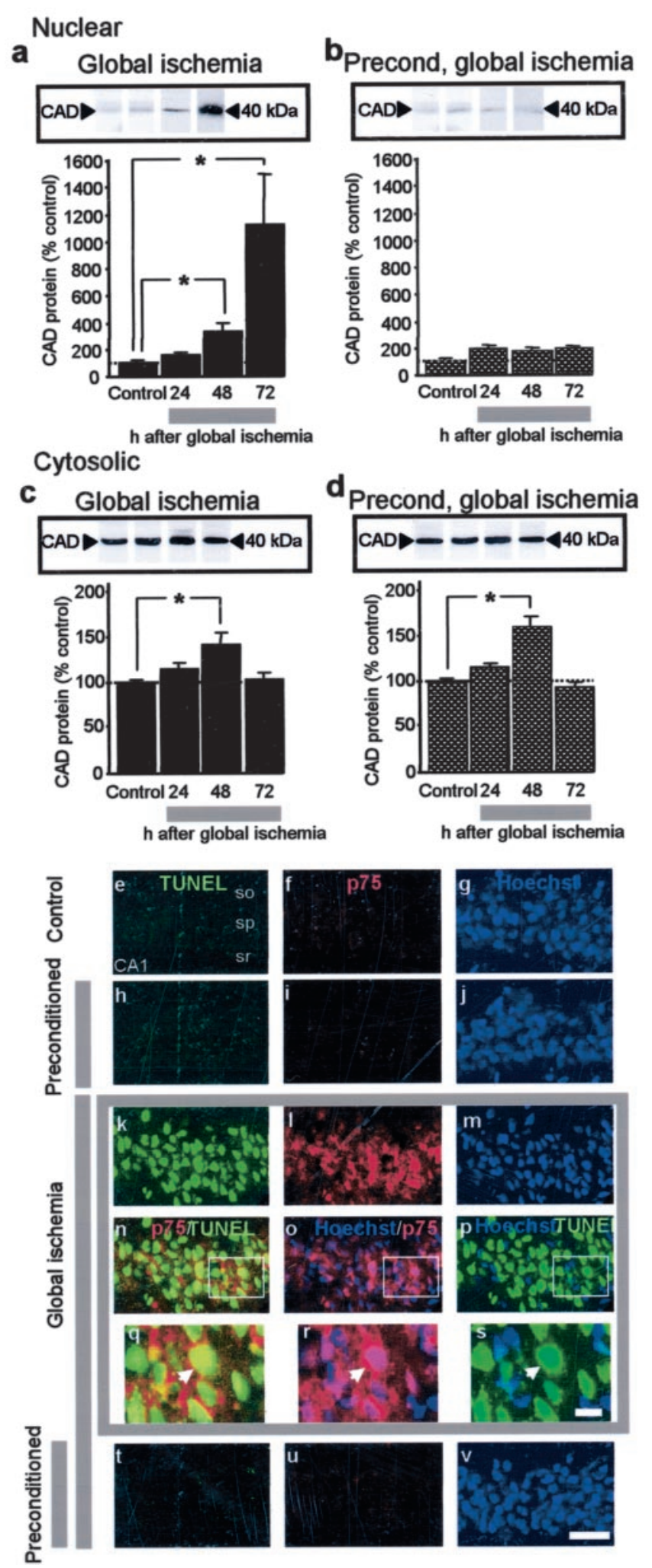

Figure 4. Preconditioning prevents ischemia-induced CAD activation, DNA fragmentation, and p75 inductinin CA1 neurons. Representative Western blots and relativeCAD protein abundancefor protein samples isolated from the nudear $(a, b)$ or cytosolic $(c, d)$ fraction of the hippocampal CA1 from animals subjected to global ischemia $(a, c)$ or preconditioning, followed by global ischemia $(b, d)$ probed with anti-CAD antibody. Mean band densities for $C A D$ in protein samples from the nudear or cytosolic fractions from experimental animals were normalized to the corresponding values for samples from control animals. Statistical significance was assessed by means of ANOVA, followed by Newman-Keuls test. Triple-labeling of TUNEL visualized in green $(e, h, k, n, p, q, t, t), \mathrm{p} 75^{\mathrm{NTR}}$ in red $(f, i, l, n, 0, p, r, u)$ and Hoechst-stained nuclei in blue $(g, j, m, 0$, $p, r, s, v)$ in the CA1 pyramidal cell layer in sections of control $(e-g)$ and experimental animals subjected findings indicate that $\mathrm{p} 75^{\mathrm{NTR}}$ expression occurs in post-ischemic CA1 neurons undergoing apoptosis. Preconditioning alone did not detectably induce $\mathrm{p} 75^{\mathrm{NTR}}$ expression or DNA fragmentation in any hippocampal subfield (Fig. $4 h-j$ ), but blocked onset of DNA fragmentation and increase in p $75^{\text {NTR }}$ expression in CA1 (Fig. $4 t-v$ ). These findings demonstrate that preconditioning intervenes upstream of CAD activation, DNA fragmentation, and p75 induction to protect CA1 neurons.

Global ischemia induces IAPs and HSP70 in naive and preconditioned neurons

We next examined the effects of preconditioning on two classes of endogenous caspase inhibitors. The IAP proteins are a family of structurally related proteins that confer protection from deathinducing stimuli by their ability to bind and reversibly inhibit activated caspases (Deveraux and Reed, 1999; Salvesen and Duckett, 2002). cIAP is a structural analog of XIAP and potent inhibitor of caspase-3 and caspase-6 (Deveraux and Reed, 1999; Salvesen and Duckett, 2002). XIAP binds and reversibly inhibits caspase-3, -7, and -9 and thereby suppresses apoptosis. Global ischemia induced a slight, but not significant, elevation in XIAP expression in the hippocampal CA1, evident at 6 and $12 \mathrm{hr}$ after reperfusion, as assessed by Western blot analysis (Fig. $5 a$ ). Ischemia in preconditioned animals did not alter XIAP abundance at $6 \mathrm{hr}$, but induced a significant reduction in XIAP abundance in CA1, evident at 12 and $24 \mathrm{hr}$ after ischemia (Fig. 5b). Global ischemia induced a pronounced increase in cIAP-2, evident at 12 hr after reperfusion (Fig. 5 c); preconditioning did not significantly alter the ischemia-induced upregulation in cIAP-2 (Fig. $5 d)$.

Heatshock proteins such as HSP70 can also halt the selfamplifying caspase death cascade and prevent apoptosis (for review, see Beere et al., 2000). HSP70 negatively regulates apoptosis by directly associating with Apaf-1 and blocking the assembly of a functional apoptosome (Beere et al., 2000; Saleh et al., 2000). Global ischemia induced a pronounced increase in HSP70 expression in CA1, evident at 6 and $12 \mathrm{hr}$ after reperfusion, as assessed by Western blot analysis (Fig. 5e); in preconditioned animals, upregulation of HSP70 was modestly greater at $6 \mathrm{hr}$ (but not $12 \mathrm{hr}$ ) after global ischemia compared with naive animals (Fig. 5f). The finding that global ischemia enhances cIAP-2 and HSP70 protein expression to the same degree in naive as in preconditioned animals strongly suggests that the two-factors together do not account for preconditioning-induced neuroprotection. There was no statistically significant difference between the preconditioned versus non-preconditioned groups for any of the factors (XIAP, cIAP, and HSP70) at any time point examined.

Preconditioning blocks ischemia-induced mitochondrial release of cytochrome $c$ and Smac/DIABLO

Injurious stimuli that are sufficiently potent promote the mitochondrial release of cytochrome $c$ and Smac/DIABLO (for review, see Hengartner, 2000). Smac/DIABLO binds to IAP family members and neutralizes their anti-apoptotic activity (Du et al., 2000; Verhagen et al., 2000). Global ischemia did not significantly alter the abundance of either cytochrome $c$ (Fig. $6 c$ ) or Smac/

$\leftarrow$

to preconditioning $(h-j)$, global ischemia $(k-s)$ or to preconditioning, followed by global ischemia at $72 \mathrm{hr}$ after the last surgery $(t-v) . n$ and $q$ are the merge of $k$ and $l ; 0$ and $r$ are the merge of $/$ and $m ; p$ and $s$ are the merge of $k$ and $m$. Boxed areas in $n-p$ are shown at higher magnification in $q-s$. Scale bars: $e-j, t-v, 40 \mu \mathrm{m} ; q-s, 10 \mu \mathrm{m}$. 
XIAP

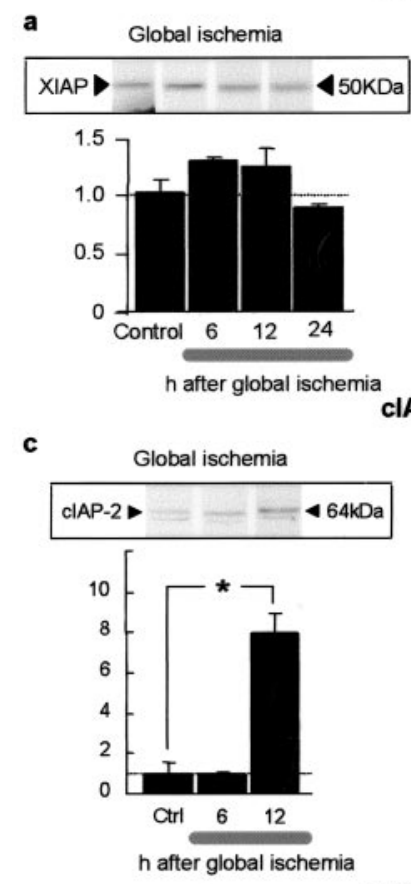

HSP70

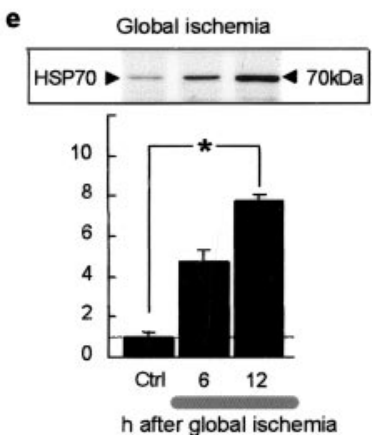

b Preconditioned, global ischemia
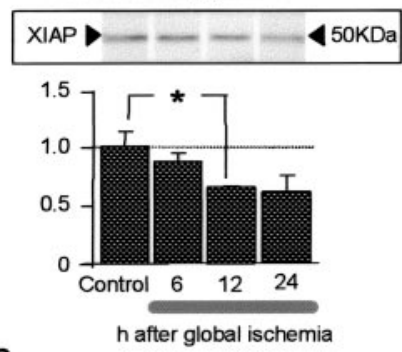

d

Preconditioned, global ischemia
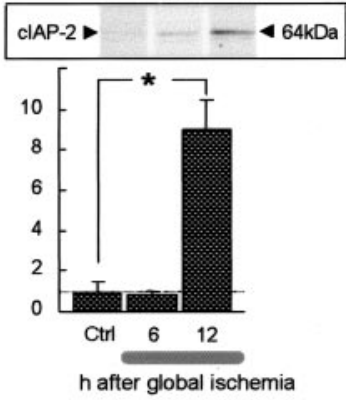

f Preconditioned, global ischemia

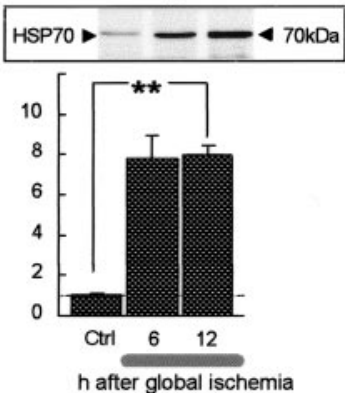

Figure 5. Global ischemia promotes expression of CIAP and HSP70 in naive and preconditioned neurons. Representative Western blots and relative XIAP, CIAP, or HSP70 abundance in protein samples isolated from the hippocampal CA1 from animals subjected to sham operation, global ischemia $(a, c, e)$, or preconditioning, followed by global ischemia $(b, d, f)$. Experimental animals were killed 6,12 , and $24 \mathrm{hr}$ after the last surgery. Westerns were probed with anti-XIAP antibody $(a, b)$, anti-cIAP antibody $(c, d)$, or anti-HSP70 antibody $(e, f)$. Mean band densities for $X I A P, ~ C I A P$, or HSP70 in protein samples from the CA1 of experimental animals were normalized to the corresponding values for samples from control animals. Statistical significance was assessed by ANOVA, followed by Newman-Keuls test $\left({ }^{* *} p<0.01\right)$.

DIABLO (Fig. $6 g$ ) in the mitochondrial fraction of the CA1, but promoted a rise in cytosolic cytochrome $c$ (Fig. 6a) and Smac/ DIABLO (Fig. 6e) from the mitochondria to the cytosol, evident at 6,12 , and $24 \mathrm{hr}$ after reperfusion, as assessed by Western blot analysis of mitochondrial and cytosolic fractions. These data are in confirmation of Sugawara et al. (2002). Preconditioning completely blocked the mitochondrial release of cytochrome $c$ (Fig. $6 b$ ) and Smac/DIABLO (Fig. 6f), evident at 6-24 hr, and induced a downregulation of cytochrome $c$ (Fig. $6 b$ ) and Smac/DIABLO (Fig. $6 f$ ) in the cytosolic fraction, evident at $12 \mathrm{hr}$, with little or no change in the mitochondrial fraction relative to that of control neurons (Fig. $6 d, h$ ). The cytosolic levels of cytochrome $c$ were significantly lower in the "preconditioned, global ischemia" versus "global ischemia" groups at $6 \mathrm{hr}(p<0.05)$ and at $12 \mathrm{hr}(p<$ 0.001 ) (Fig. 6a,b). The cytosolic levels of Smac/DIABLO were significantly lower in the "preconditioned, global ischemia" ver-

\section{Cytochrome $c$}

${ }^{a}$ Cytosolic

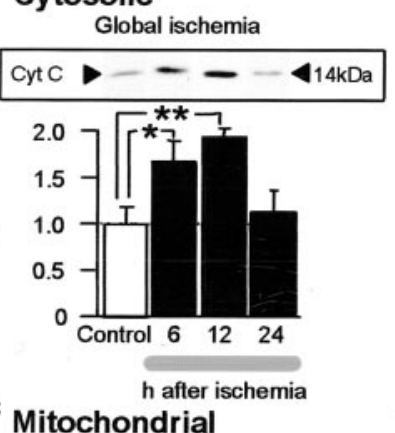

Preconditioned, global ischemia

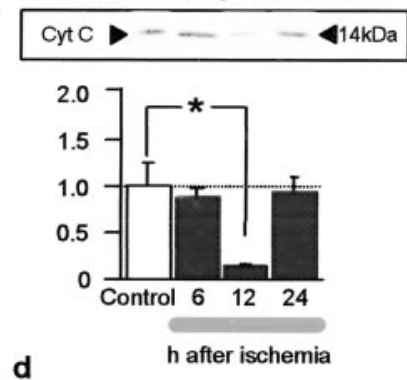

d

Global ischemia

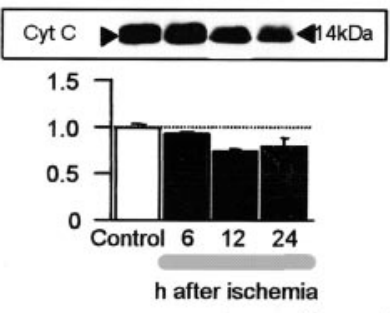

Preconditioned, global ischemia

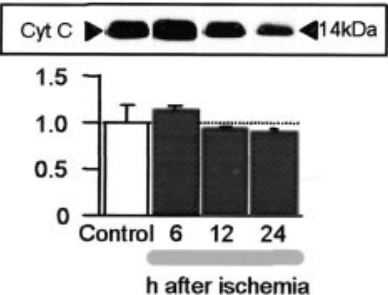

Smac/DIABLO

e Cytosolic

f

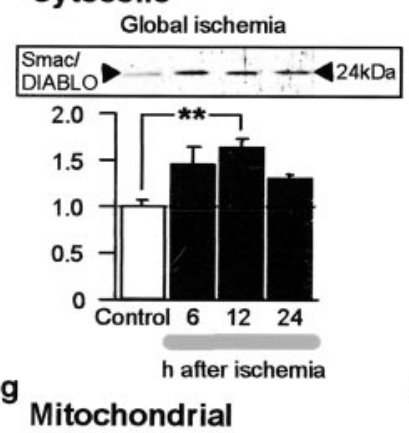

Preconditioned, global ischemia

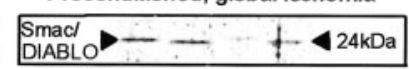

Smacl
DIABLO - $+424 \mathrm{kDa}$

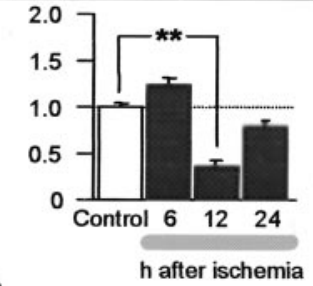

h

Preconditioned, global ischemia
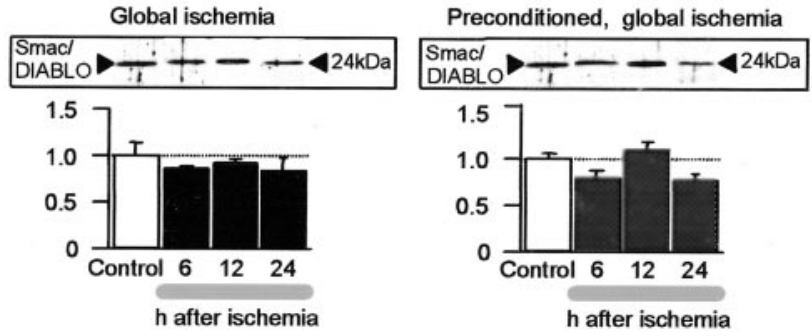

Figure 6. Preconditioning blocks the ischemia-induced mitochondrial release of cytochrome $c$ and Smac/DIABLO. Representative Western blots and relative abundance of cytochrome $c$ or Smac/DIABLO in the cytosolic $(a, b, e, f)$ and mitochondrial $(c, d, g, h)$ fractions of protein samples isolated from the hippocampal CA1 from animals subjected to sham operation, global ischemia $(a, c, e, g)$, or preconditioning followed by global ischemia $(b, d, f, h)$. Experimental animals were killed 6,12 , and $24 \mathrm{hr}$ after the last surgery. Westerns were probed with anti-cytochrome c antibody $(a-d)$ or anti-Smac/DIABLO antibody $(e-h)$. Mean band densities for cytochrome $c$ or Smac/DIABL0 in protein samples from the CA1 of experimental animals were normalized to the corresponding values for samples from control animals. Statistical significance was assessed by ANOVA, followed by Newman-Keuls test ( ${ }^{* *} p<0.01$ ).

sus "global ischemia" groups at $12 \mathrm{hr}(p<0.001)$ and at $24 \mathrm{hr}$ $(p<0.05)$ (Fig. 6e,f). Together, these findings suggest that preconditioning prevents the release of cytochrome $c$ and Smac/ DIABLO, consistent with a model whereby preconditioning preserves the integrity of the mitochondrial membrane in the face of 
ischemic insults and may promote degradation of cytochrome $c$ and Smac/DIABLO in the cytoplasm.

\section{Discussion}

Apoptosis is an evolutionarily conserved process that is crucial for tissue development and homeostasis in eukaryotic organisms that, when dysregulated, can elicit inappropriate cell death. Global ischemia is a neuronal insult that induces apoptotic death. Ischemic preconditioning is a paradigm that affords robust protection of CA1 neurons against ischemic death for up to $14 \mathrm{~d}$ (for review, see Kirino, 2002). A major conclusion of the present study is that preconditioning intervenes downstream of caspase-3 activation and upstream of ICAD cleavage and DNA fragmentation to inhibit caspase- 3 functional activity. In animals subjected to preconditioning followed by global ischemia, caspase- 3 activity is pronounced and transient in CA1 neurons, which are protected and survive. Moreover, caspase-3 does not modify downstream targets, such as ICAD, presumably because of insufficient time, rather than activity level which at $6 \mathrm{hr}$ is as high in preconditioned animals as in naive animals subjected to global ischemia. Although the present study does not directly examine whether caspase-3 activation is required for neuroprotection, clearly the window of neuroprotection afforded by ischemic preconditioning persists for many days (Kirino, 2002) after caspase-3 activity is extinguished. Interestingly, induction of brief (sublethal) focal ischemia in vivo (and brief chemical ischemia in cortical neurons in vitro) induce sustained caspase- 3 activation in cortical neurons that survive; in these paradigms caspase- 3 activation and PARP-1 cleavage are required for neuroprotection (Garnier et al., 2003; McLaughlin et al., 2003). The finding of a commonality between focal and global ischemia, namely neuronal survival in the face of caspase- 3 activation, is unexpected in that the paradigms target different populations of neurons and induce cell death via different mechanisms. The finding that neurons survive functional activation of caspase- 3 is unexpected in that caspase- 3 has been considered essential and sufficient for the execution of apoptosis (for review, see Cohen, 1997; Nicholson and Thornberry, 1997; Hengartner, 2000).

\section{Derailing caspase-3-induced neuronal death}

How then can neurons survive caspase- 3 activation? A second major conclusion of the present study is that global ischemia promotes expression of negative modulators of apoptosis in both naive and preconditioned animals. The IAPs are a family of prosurvival genes that act downstream of caspase cleavage to directly bind and inhibit activated caspases and halt the caspase death cascade (for review, see Deveraux et al., 1997; Salvesen and Duckett, 2002). cIAP is known to potently bind and inhibit caspase-3. Global ischemia rapidly upregulates cIAP in selectively vulnerable CA1 neurons of naive and preconditioned animals with a time course that parallels that of the decline in caspase- 3 activity in preconditioned animals. In contrast, XIAP is downregulated in CA1 neurons (present study), and NAIP is upregulated in resistant thalamic neurons, but not vulnerable CA1 neurons (Xu et al., 1997). The present study also shows that global ischemia promotes expression of HSP70 in CA1 neurons. HSP70 is a chaperone protein, which negatively regulates apoptosis by binding Apaf- 1 and inhibiting formation of the apoptosome (Beere et al., 2000) and by blocking the release of cytochrome $\mathrm{c}$ from the mitochondria (Tsuchiya et al., 2003). Although these factors could act upstream of procaspse- 3 cleavage, our findings that caspase- 9 and -3 are cleaved and activated at $6 \mathrm{hr}$ after global ischemic insult of preconditioned neurons clearly indicate that in this paradigm

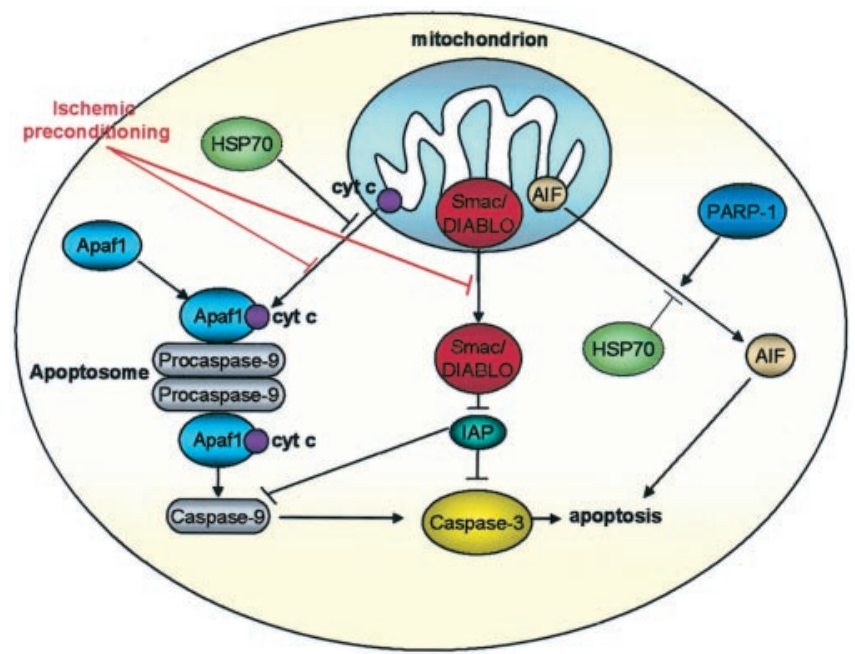

Figure 7. Representative scheme showing that preconditioning prevents initiation of the intrinsic (mitochondrial) pathway of caspase activation. Injurious stimuli such as global ischemia promote the coordinated release of cytochrome c and Smac/DIABLO from the mitochondria (for review, see Hengartner, 2000). Once in the cytoplasm, cytochrome c assembles with the apoptotic protease activating factor 1 (Apaf-1), procaspase- 9 and (d)ATP to form the apoptosome. Formation of the apoptosome promotes activation of procaspase- 9 by Apaf- 1 . Activated caspase- 9 , in turn, cleaves procaspase- 3 to generate the downstream "terminator" protein caspase-3. Injurious stimuli also upregulate IAPs, which bind and inhibit activated caspases, thereby squelching the caspase cascade. Smac/DIABLO neutralizes the protective effects of IAPs by directly binding them and disengaging them from activated caspases, enabling the caspase death cascade to induce apoptotic cell death. Heat shock protein 70 (HSP70) inhibits the oligomerization of Apaf- 1 and the release of cytochrome c from the mitochondria; HSP70 also inhibits release of apoptosis-inducing factor (AIF), thus inhibiting apoptosis. The breakdown of the mitochondrial outer membrane can be blocked by a number of events including upregulation of anti-apoptotic $\mathrm{BCl}-2$ family members and phosphorylation of the proapoptotic family member BAD. Arrows indicate the activation of targets, whereas lines with blunted ends indicate their inactivation. (adapted from Zimmermann et al., 2001).

they do not. Moreover, the finding that global ischemia increases cIAP-2 and HSP70 expression to nearly the same degree in naive as in preconditioned animals argues that yet another factor is required for protection.

An inferred conclusion of the present study is that preconditioning preserves the integrity of the mitochondrial membrane in the face of ischemic insults and thereby enables CA1 neurons to survive. Injurious stimuli such as global ischemia disrupt the integrity of the outer mitochondrial membrane and enable the release of cytochrome $c$ and Smac/DIABLO (Sugawara et al., 2002) (Fig. 7). Smac/DIABLO binds IAPs and disengages them from activated caspases, thus promoting caspase activity and enabling the execution of apoptosis (Du et al., 2000; Verhagen et al., 2000). The interplay between the IAPs and Smac/DIABLO establishes a threshold for "lethal" caspase-3 activity. Findings in the present study show that preconditioning blocks the release of cytochrome $c$ and Smac/DIABLO. Moreover, animals subjected to preconditioning followed by global ischemia exhibit reduced levels of cytosolic Smac/DIABLO relative to control animals at 12 $\mathrm{hr}$; the observed decrease in Smac/DIABLO could arise as a consequence of increased (regulated) degradation and/or reduced release of Smac/DIABLO relative to that of control neurons. In the absence of Smac/DIABLO, IAPs bind activated caspase- 3 and halt the caspase cascade (Fig. 7, model). An important prediction from the present study is that the unleashing of Smac/DIABLO is critical for global ischemia-induced (caspase-3-dependent) neuronal death.

Although the precise mechanisms by which mitochondrial 
membrane breaks down are unknown, dephosphorylation of the pro-apoptotic Bcl-2 family member BAD is thought to play a critical role (for review, see Hengartner, 2000; Kroemer and Reed, 2000). Global ischemia induces sustained high cytoplasmic $\mathrm{Ca}^{2+}$, which triggers activation of the protein phosphatase calcineurin (Wang et al., 1999; Hengartner, 2000). After activation, calcineurin dephosphorylates $\mathrm{BAD}$, promoting its release from cytosolic retention factor 14-3-3 and translocation to the mitochondria, where it heterodimerizes with anti-apoptotic Bcl-2 family members such as $\mathrm{Bcl}-\mathrm{x}_{\mathrm{L}}$ or Bcl- $\mathrm{x}_{\mathrm{L}}$ and initiates the mitochondrial permeability transition (Wang et al., 1999). A possible scenario is that preconditioning acts via the phosphotidylinositol 3-kinase (PI3K)/protein kinase B (Akt) signaling system to promote $\mathrm{BAD}$ phosphorylation.

\section{Global ischemia induces apoptosis via the mitochondrial route}

Caspase- 3 can be activated by both extrinsic (receptor-mediated) and intrinsic (or mitochondria-mediated) signaling pathways. The finding that global ischemia in naive animals promotes Fas mRNA expression (Jin et al., 2001) and $p 75^{\mathrm{NTR}}$ protein expression (present study) many hours after caspase-3 activation argue against the extrinsic pathway of caspase-3 activation. The finding that global ischemia in naive and preconditioned animals elicits mitochondrial release and activation of caspase- 9 at a time before activation of caspase-3 is consistent with the notion that caspase- 3 is activated via caspase- 9 and the mitochondrial route. The finding that preconditioning elicits mitochondrial release and activation of caspase-9 in the apparent absence of detectable cytosolic cytochrome $c$ is somewhat unexpected. One possibility is that preconditioning elicits a transient release of a low, but evidently effective, level of cytochrome $c$ together with procaspase- 9 from the mitochondria to the cytosol, resulting in limited apoptosome formation. Indeed, recent findings suggest the existence of caspase-dependent amplification loops that feed back on the mitochondria to amplify an initial wave of caspsase- 9 activation; thus, the apoptosome may serve not only to initiate, but also to amplify the caspase cascade (Creagh et al., 2003). Another possibility is that caspase- 9 is activated via a cytochrome $c$-independent route. Hints of cytochrome $c$-independent mechanisms of caspase- 9 activation come from observations that truncation mutants of Apaf- 1 bind and activate pro-caspase-9 in the absence of cytochrome $c$ (Srinivasula et al., 1998) and that caspase- 12 activates caspase- 9 in a cytochrome $c$-independent (and Apaf-1-independent) manner (Nakagawa et al., 2000; Morishima et al., 2002; Rao et al., 2002). A possible scenario is that global ischemia activates the proteolytic enzyme calpain (Neumar et al., 2001), which then activates caspase-12 (Nakagawa et al., 2000).

In summary, the present study shows that ischemic preconditioning acts downstream of caspase- 3 activation and upstream of its target CAD to prevent the onset of apoptotic cell death. Importantly, preconditioned neurons subjected to lethal insult survive transient, potent caspase-3 activity. Our findings suggest that preconditioning preserves the integrity of the mitochondrial membrane in the face of ischemic insults and thereby enables CA1 neurons to survive caspase activation. In contrast, estrogen at neuroprotective doses blocks caspase-3 activation (Jover et al., 2002). Thus, diverse protective strategies intervene at different steps in the caspase cascade. An understanding of the molecular mechanisms underlying ischemic tolerance may help in the design of novel neuroprotective strategies for intervention in the neuronal death associated with stroke and other neurological disorders. Arrest of apoptotic cell death downstream of caspase-3 activation provides a potentially important mechanism of neuronal survival in the face of injurious stimuli.

\section{References}

Beere HM, Wolf BB, Cain K, Mosser DD, Mahboubi A, Kuwana T, Tailor P, Morimoto RI, Cohen GM, Green DR (2000) Heat-shock protein 70 inhibits apoptosis by preventing recruitment of procaspase- 9 to the Apaf-1 apoptosome. Nat Cell Biol 2:469-475.

Calderone A, Jover T, Noh K-M, Tanaka H, Yokota H, Lin Y, Grooms S, Regis R, Bennett MVL, Zukin RS (2003) Ischemic insults de-repress the gene silencer rest in neurons destined to die. J Neurosci 23:2112-2121.

Cao G, Pei W, Lan J, Stetler RA, Luo Y, Nagayama T, Graham SH, Yin XM, Simon RP, Chen J (2001) Caspase-activated DNase/DNA fragmentation factor 40 mediates apoptotic DNA fragmentation in transient cerebral ischemia and in neuronal cultures. J Neurosci 21:4678-4690.

Chen J, Nagayama T, Jin K, Stetler RA, Zhu RL, Graham SH, Simon RP (1998) Induction of caspase-3-like protease may mediate delayed neuronal death in the hippocampus after transient cerebral ischemia. J Neurosci 18:4914-4928.

Cohen GM (1997) Caspases: the executioners of apoptosis. Biochem J 326:1-16.

Creagh EM, Conroy H, Martin SJ (2003) Caspase-activation pathways in apoptosis and immunity. Immunol Rev 193:10-21.

Deveraux QL, Reed JC (1999) IAP family proteins-suppressors of apoptosis. Genes Dev 13:239-252.

Deveraux QL, Takahashi R, Salvesen GS, Reed JC (1997) X-linked IAP is a direct inhibitor of cell-death proteases. Nature 388:300-304.

Du C, Fang M, Li Y, Li L, Wang X (2000) Smac, a mitochondrial protein that promotes cytochrome $c$-dependent caspase activation by eliminating IAP inhibition. Cell 102:33-42.

Garnier P, Ying W, Swanson RA (2003) Ischemic preconditioning by caspase cleavage of poly(ADP-ribose) polymerase-1. J Neurosci 23:7967-7973.

Gidday JM, Shah AR, Maceren RG, Wang Q, Pelligrino DA, Holtzman DM, Park TS (1999) Nitric oxide mediates cerebral ischemic tolerance in a neonatal rat model of hypoxic preconditioning. J Cereb Blood Flow Metab 19:331-340.

Grabb MC, Choi DW (1999) Ischemic tolerance in murine cortical cell culture: critical role for NMDA receptors. J Neurosci 19:1657-1662.

Graham SH, Chen J (2001) Programmed cell death in cerebral ischemia. J Cereb Blood Flow Metab 21:99-109.

Hara H, Friedlander RM, Gagliardini V, Ayata C, Fink K, Huang Z, ShimizuSasamata M, Yuan J, Moskowitz MA (1997) Inhibition of interleukin 1beta converting enzyme family proteases reduces ischemic and excitotoxic neuronal damage. Proc Natl Acad Sci USA 94:2007-2012.

Hengartner MO (2000) The biochemistry of apoptosis. Nature 407:770-776.

Henshall DC, Bonislawski DP, Skradski SL, Araki T, Lan JQ, Schindler CK, Meller R, Simon RP (2001) Formation of the Apaf-1/cytochrome $c$ complex precedes activation of caspase- 9 during seizure-induced neuronal death. Cell Death Differ 8:1169-1181.

Heurteaux C, Lauritzen I, Widmann C, Lazdunski M (1995) Essential role of adenosine, adenosine Al receptors, and ATP-sensitive $\mathrm{K}^{+}$channels in cerebral ischemic preconditioning. Proc Natl Acad Sci USA 92:4666-4670.

Jin K, Graham SH, Mao X, Nagayama T, Simon RP, Greenberg DA (2001) Fas (CD95) may mediate delayed cell death in hippocampal CA1 sector after global cerebral ischemia. J Cereb Blood Flow Metab 21:1411-1421.

Jover T, Tanaka H, Calderone A, Oguro K, Bennett MVL, Etgen AM, Zukin RS (2002) Estrogen protects against global ischemia-induced neuronal death and prevents activation of apoptotic signaling cascades in the hippocampal CA1. J Neurosci 22:2115-2124.

Kaplan DR, Miller FD (1997) Signal transduction by the neurotrophin receptors. Curr Opin Cell Biol 9:213-221.

Kawahara N, Croll SD, Wiegand SJ, Klatzo I (1997) Cortical spreading depression induces long-term alterations of BDNF levels in cortex and hippocampus distinct from lesion effects: implications for ischemic tolerance. Neurosci Res 29:37-47.

Kinouchi H, Sharp FR, Koistinaho J, Hicks K, Kamii H, Chan PH (1993) Induction of heat shock hsp70 mRNA and HSP70 kDa protein in neurons in the "penumbra" following focal cerebral ischemia in the rat. Brain Res 619:334-338. 
Kirino T (2002) Ischemic tolerance. J Cereb Blood Flow Metab 22:1283-1296.

Kirino T, Tsujita Y, Tamura A (1991) Induced tolerance to ischemia in gerbil hippocampal neurons. J Cereb Blood Flow Metab 11:299-307.

Kitagawa K, Matsumoto M, Kuwabara K, Tagaya M, Ohtsuki T, Hata R, Ueda H, Handa N, Kimura K, Kamada T (1991) "Ischemic tolerance" phenomenon detected in various brain regions. Brain Res 561:203-211.

Krajewski S, Krajewska M, Ellerby LM, Welsh K, Xie Z, Deveraux QL, Salvesen GS, Bredesen DE, Rosenthal RE, Fiskum G, Reed JC (1999) Release of caspase- 9 from mitochondria during neuronal apoptosis and cerebral ischemia. Proc Natl Acad Sci USA 96:5752-5757.

Kroemer G, Reed JC (2000) Mitochondrial control of cell death. Nat Med 6:513-519.

Li P, Nijhawan D, Budihardjo I, Srinivasula SM, Ahmad M, Alnemri ES, Wang X (1997) Cytochrome $c$ and dATP-dependent formation of Apaf$1 /$ caspase- 9 complex initiates an apoptotic protease cascade. Cell 91:479-489.

Liu X, Kim CN, Pohl J, Wang X (1996) Purification and characterization of an interleukin-1beta-converting enzyme family protease that activates cysteine protease P32 (CPP32). J Biol Chem 271:13371-13376.

Liu Y, Kato H, Nakata N, Kogure K (1992) Protection of rat hippocampus against ischemic neuronal damage by pretreatment with sublethal ischemia. Brain Res 586:121-124.

MacManus JP, Buchan AM (2000) Apoptosis after experimental stroke: fact or fashion? J Neurotrauma 17:899-914.

McLaughlin B, Hartnett KA, Erhardt JA, Legos JJ, White RF, Barone FC, Aizenman E (2003) Caspase 3 activation is essential for neuroprotection in preconditioning. Proc Natl Acad Sci USA 100:715-720.

Morishima N, Nakanishi K, Takenouchi H, Shibata T, Yasuhiko Y (2002) An endoplasmic reticulum stress-specific caspase cascade in apoptosis. Cytochrome $c$-independent activation of caspase- 9 by caspase-12. J Biol Chem 277:34287-34294

Nagata S (2000) Apoptotic DNA fragmentation. Exp Cell Res 256:12-18.

Nakagawa T, Zhu H, Morishima N, Li E, Xu J, Yankner BA, Yuan J (2000) Caspase-12 mediates endoplasmic-reticulum-specific apoptosis and cytotoxicity by amyloid-beta. Nature 403:98-103.

Neumar RW, Meng FH, Mills AM, Xu YA, Zhang C, Welsh FA, Siman R (2001) Calpain activity in the rat brain after transient forebrain ischemia. Exp Neurol 170:27-35.

Nicholson DW, Thornberry NA (1997) Caspases: killer proteases. Trends Biochem Sci 22:299-306.

Nishi S, Taki W, Uemura Y, Higashi T, Kikuchi H, Kudoh H, Satoh M, Nagata K (1993) Ischemic tolerance due to the induction of HSP70 in a rat ischemic recirculation model. Brain Res 615:281-288.

Opitz T, Grooms SY, Bennett MVL, Zukin RS (2000) Remodeling of alphaamino-3-hydroxy-5-methyl-4-isoxazole-propionic acid receptor subunit composition in hippocampal neurons after global ischemia. Proc Natl Acad Sci USA 97:13360-13365.

Ouyang YB, Tan Y, Comb M, Liu CL, Martone ME, Siesjo BK, Hu BR (1999) Survival- and death-promoting events after transient cerebral ischemia: phosphorylation of Akt, release of cytochrome $c$ and activation of caspaselike proteases. J Cereb Blood Flow Metab 19:1126-1135.

Pulsinelli WA, Brierley JB, Plum F (1982) Temporal profile of neuronal damage in a model of transient forebrain ischemia. Ann Neurol 11:491-498.

Rao RV, Castro-Obregon S, Frankowski H, Schuler M, Stoka V, del Rio G,
Bredesen DE, Ellerby HM (2002) Coupling endoplasmic reticulum stress to the cell death program. An Apaf-1-independent intrinsic pathway. J Biol Chem 277:21836-21842.

Riepe MW, Esclaire F, Kasischke K, Schreiber S, Nakase H, Kempski O, Ludolph AC, Dirnagl U, Hugon J (1997) Increased hypoxic tolerance by chemical inhibition of oxidative phosphorylation: "chemical preconditioning." J Cereb Blood Flow Metab 17:257-264.

Roux PP, Colicos MA, Barker PA, Kennedy TE (1999) p75 neurotrophin receptor expression is induced in apoptotic neurons after seizure. J Neurosci 19:6887-6896.

Saleh A, Srinivasula SM, Balkir L, Robbins PD, Alnemri ES (2000) Negative regulation of the Apaf-1 apoptosome by Hsp70. Nat Cell Biol 2:476-483.

Salvesen GS, Duckett CS (2002) IAP proteins: blocking the road to death's door. Nat Rev Mol Cell Biol 3:401-410.

Simon RP, Niiro M, Gwinn R (1993) Prior ischemic stress protects against experimental stroke. Neurosci Lett 163:135-137.

Srinivasula SM, Ahmad M, Fernandes-Alnemri T, Alnemri ES (1998) Autoactivation of procaspase- 9 by Apaf-1-mediated oligomerization. Mol Cell 1:949-957.

Sugawara T, Fujimura M, Morita-Fujimura Y, Kawase M, Chan PH (1999) Mitochondrial release of cytochrome $c$ corresponds to the selective vulnerability of hippocampal CA1 neurons in rats after transient global cerebral ischemia. J Neurosci 19:RC39.

Sugawara T, Noshita N, Lewen A, Gasche Y, Ferrand-Drake M, Fujimura M, Morita-Fujimura Y, Chan PH (2002) Overexpression of copper/zinc superoxide dismutase in transgenic rats protects vulnerable neurons against ischemic damage by blocking the mitochondrial pathway of caspase activation. J Neurosci 22:209-217.

Tanaka H, Calderone A, Jover T, Grooms SY, Yokota H, Zukin RS, Bennett MV (2002) Ischemic preconditioning acts upstream of GluR2 downregulation to afford neuroprotection in the hippocampal CA1. Proc Natl Acad Sci USA 99:2362-2367.

Tsuchiya D, Hong S, Matsumori Y, Shiina H, Kayama T, Swanson RA, Dillman WH, Liu J, Panter SS, Weinstein PR (2003) Overexpression of rat heat shock protein 70 is associated with reduction of early mitochondrial cytochrome $c$ release and subsequent DNA fragmentation after permanent focal ischemia. J Cereb Blood Flow Metab 23:718-727.

Verhagen AM, Ekert PG, Pakusch M, Silke J, Connolly LM, Reid GE, Moritz RL, Simpson RJ, Vaux DL (2000) Identification of DIABLO, a mammalian protein that promotes apoptosis by binding to and antagonizing IAP proteins. Cell 102:43-53.

Wang HG, Pathan N, Ethell IM, Krajewski S, Yamaguchi Y, Shibasaki F, McKeon F, Bobo T, Franke TF, Reed JC (1999) $\mathrm{Ca}^{2+}$-induced apoptosis through calcineurin dephosphorylation of BAD. Science 284:339-343.

Xu DG, Crocker SJ, Doucet JP, St. Jean M, Tamai K, Hakim AM, Ikeda JE, Liston P, Thompson CS, Korneluk RG, MacKenzie A, Robertson GS (1997) Elevation of neuronal expression of NAIP reduces ischemic damage in the rat hippocampus. Nat Med 3:997-1004.

Yamashima T (2000) Implication of cysteine proteases calpain, cathepsin and caspase in ischemic neuronal death of primates. Prog Neurobiol 62:273-295.

Zimmermann KC, Bonzon C, Green DR (2001) The machinery of programmed cell death. Pharmacol Ther 92:57-70.

Zou H, Henzel WJ, Liu X, Lutschg A, Wang X (1997) Apaf-1, a human protein homologous to C. elegans CED-4, participates in cytochrome $c$-dependent activation of caspase-3. Cell 90:405-413. 